\title{
DEGRADAÇÃO DE AMETRINA EM AREIA QUARTZOSA COM ADIÇÃO DE SOLO RIZOSFÉRICO DE CANA-DE-AÇÚCAR ${ }^{(1)}$
}

\author{
M. A. $\operatorname{COSTA}^{(2)}$, R.T.R. MONTEIRO(3) $\&$ V.L.TORNISIELO $0^{(4)}$
}

\begin{abstract}
RESUMO
Utilizando amostras de Areia Quartzosa esterilizada, não esterilizada e com adição de $10 \%$ de solo da rizosfera de cana-de-açúcar cultivada em campo, na presença e na ausência do herbicida ametrina, a biodegradação de ${ }^{14} \mathrm{C}$-ametrina foi avaliada juntamente com a quantidade de resíduos extraíveis, não-extraíveis e número de microrganismos presentes. A taxa de desprendimento de ${ }^{14} \mathrm{CO}_{2}$ aumentou em 3,5 vezes, com adição de solo rizosférico de culturas previamente tratadas com o herbicida, em 1,7 vez, com a adi ção de solo de rizosfera de culturas não tratadas. A presença de metabóli tos detectada por cromatografia de camada delgada revela a maior degradação nas amostras que tiveram a adição de solo rizosférico. A microbiota presente na rizosfera ocasionou maior mineralização do herbicida ametrina.
\end{abstract}

Termos de indexação:mineralização, herbicida, fitorremediação, biorremediação

\section{SUMMARY: EFFECT OF RHIZOSPHERE SOIL ADDITION ON AMETRYN DEGRADATION IN SANDY SOIL}

Theeffect of rhizospheresoil addition on ametryn degradation ratewas eval uated. The ${ }^{14} \mathrm{CO}_{2}$ rel ease ratefrom sterile and non-sterile samples of a sandy soil was compared with the same soil amended with $10 \%$ rhizosphere soil from a sugar-cane plantation, treated or not with ametryn. Sterilized soils showed very low ${ }^{14} \mathrm{CO}_{2}$ release as compared with nonsterilized soil. When mineralization of non-amended soil was compared with rhizosphere soil amended from treated and non-treated fiedds, 3.5 and 1.7 fold increases of mineralization, respectively, were observed in amended soil. Extract TLC showed more degradation on

\footnotetext{
(1) Parte da Tese de Mestrado apresentada pelo primeiro autor ao Centro de Energia Nuclear na Agricultura - CENA/USP. Recebido para publicação em maio de 1997 e aprovado em dezembro de 1999.

(2) Bióloga - PG - Centro de Energia Nuclear na Agricultura, CENA/USP. Av. Centenário 303, Caixa Postal 96, CEP 13400-970 Piracicaba (SP).

(3) Bióloga - Pesquisador, CENA/USP. Email: monteiro@cena.usp.br.

(4) Ecólogo - Pesquisador, CENA/USP. Email: vtornis@cena.usp.br.
} 
amended samples than on non-amended samples. These results suggest that ametryn is degraded mainly through microbial action and that amendment with soil microbial population from ametryn pretreated soil increases this herbicide's degradation rate.

Index terms: mineralization, herbicide, phytoremediation, bioremediation.

\section{NTRODUÇÃO}

O herbicida ametrina tem seu uso recomendado para culturas decana-de-açúcar, milho, banana, café, citros e uva (Rodrigues \& Almeida, 1995). Sua persistência no solo é alta (Leon et al., 1978), especialmente em sol os com altos teores de argila e matéria orgânica (Lui \& Cibes-Viadé, 1972). Em solos brasileiros, a persistência de ametrina varia conforme o tipo de solo e adição de substrato orgânico, sendo classificada como alta (Compte, 1997, Prata, 1998) e média (Costa, 1992, Rodrigues \& Almeida, 1995, Costa et al., 1997, Prata, 1998).

A mineralização de ametrina foi aumentada de 12 a 13 vezes em Areia Quartzosa (o mesmo solo utilizado neste trabalho) quando $10 \%$ de palha de cana-de-açúcar foi adicionada, não exercendo influência no desprendimento de ${ }^{14} \mathrm{CO}_{2}$ a aplicação prévia de ametrina no campo (Costa et al., 1997). Neste caso, a maior atividade microbiana mostrouse responsável pela degradação de ametrina.

A degradação de ametrina em meio de cultura líqui do foi observada em culturas mistas de bactérias por Kontchou \& Gschwind (1999) e Gebendinger \& Radosevich (1999), que isolaram culturas de bactérias degradadoras de atrazina. Observou-seque otratamento prévio do meio com her bi ci das do grupo das triazinas não resultou em isol amento de culturas degradadoras de atrazina, mas o tratamento prévio com atrazina ou simazina resultou em culturas degradadoras de atrazina.

A rizosfera é uma região de atividade e crescimento mi crobiano aumentado em comparação com regiões do solo sem interferências de raízes. A excreção de exudados de raízes das plantas contribui para este aumento, e o aumento no número e composição dos microrganismos da rizosfera depende da espécie, idade da planta e tipo de solo (Campbell, 1985), bem como de outros fatores, como a exposi ção da planta a xenobióticos (Cunnigham et al., 1996). I nfluência direta na qualidade de exudados, bem como na microbiota rizosférica, após aplicação de pesticidas, foi anteriormente observada por Balasubramanian \& Rangaswani (1973), AbdelNasser et al. (1979) e Sandmann \& Loos (1984). Anderson et al. (1993) observaram um aumento na degradação dos herbicidas metolacloro, atrazina e trifluralina, quando compararam solos rizosféricos de Kochia sp com sol os não-rizosféricos. A degradação acelerada de alaclor também foi observada por Zablotowiez et al. (1995), utilizando Pseudomonas spp. fluorescentes recuperadas de rizosfera.

O objetivo deste estudo foi investigar o processo de degradação de ametrina sob a influência da microbiota rizosférica de cana-de-açúcar cultivada na presença e na ausência do herbicida ametrina, para isto foi utilizada o ${ }^{14} \mathrm{C}$ ametrina como traçador.

\section{MATERIAL E MÉTODOS}

Amostras de Areia Quartzosa (AQ) foram col etadas na profundidade de $0-20 \mathrm{~cm}$, no município deCharqueada, SP. Sol os de rizosfera (SR) de canade-açúcar cultivada na ausência deherbicida (SR) e com aplicação prévia do herbicida ametrina (SRH) foram col etados em plantação de cana-de-açúcar, no ano de 1991, três meses após a última aplicação, em uma área onde a ametrina (Gesapax 800 PM) havia sido aplicada por dois anos consecutivos, na taxa de $4 \mathrm{~kg}$ ha-1 ano-1. Os solos rizosféricos foram provenientes da fazenda da Usina Santa Bárbara, no muníci pio de Santa Bárbara D'Oeste (SP).

As análises químicas dos solos $\mathrm{AQ}, \mathrm{SRH}$ e SR encontram-se no quadro 1.

Amostras de $10 \mathrm{~g}$ de solo, com quatrotratamentos e cinco repetições, foram distribuídas em frascos de vidro, seguindo um delineamento experimental inteiramente casualizado:

Tratamento 1:10 g solo AQ,

Tratamento $2: 9 \mathrm{~g}$ solo AQ + $1 \mathrm{gSR}$,

Tratamento 3:9 g solo AQ + $1 \mathrm{~g} \mathrm{SRH,}$

Tratamento 4: $10 \mathrm{~g}$ solo AQ Esterilizada

O teor de umidade das amostras de solo foi ajustado para $70 \%$ da capacidade de campo e foi corrigido, semanal mente, por gravimetria. Os frascos foram fechados, pesados e deixados em ambiente escuro a $23^{\circ} \mathrm{C}$, por um período de sete dias. Cinco frascos foram esterilizados em autoclave a $120^{\circ} \mathrm{C}$, durante uma hora, por três dias consecutivos. Após reativação do solo, aplicou-se $1 \mathrm{~mL}$ de solução de ametrina (2-metiltio-4-etilamino-6-isopropilamino), na concentração de $8,3 \mu \mathrm{g} \mathrm{mL}-1$ e atividade de 800 Bq mL-1, em todos os tratamentos (IBAMA, 1990). 


\section{Quadro 1. Análise química de Areia Quartzosa (AQ), solo rizosférico não tratado (SR) e solo rizosférico tratado com ametrina (SR H)}

\begin{tabular}{|c|c|c|c|c|c|c|c|c|c|c|}
\hline Solo & $\mathbf{P}(1)$ & $\mathbf{p H}$ & M.O. & K & $\mathrm{Ca}$ & Mg & $\mathbf{H}+\mathbf{A} \mathbf{I}$ & $\mathbf{s}$ & $\mathbf{T}$ & V\% \\
\hline & & $\mathrm{CaCl}_{2}$ & $\%$ & & & & eq/100 m & & & \\
\hline $\mathrm{AQ}$ & 11,3 & 5,3 & 1,75 & 0,24 & 1,76 & 0,18 & 1,64 & 2,2 & 3,8 & 57,1 \\
\hline$S R$ & 18,1 & 4,5 & 3,33 & 0,11 & 1,61 & 0,72 & 5,8 & 2,4 & 8,2 & 29,6 \\
\hline SRH & 17,8 & 4,6 & 3,20 & 0,24 & 1,81 & 0,84 & 4,23 & 2,9 & 7,1 & 40,6 \\
\hline
\end{tabular}

O herbicida ${ }^{14} \mathrm{C}$-ametrina radiomarcado uniformemente em todos os carbonos do anel foi fornecido pela Ciba-Geigy Corporation, Depto de Síntese Química e Dow Chemical Company, Midland, USA, com atividade específica de 26, $71 \mu \mathrm{Ci} \mathrm{mg-1} \mathrm{e} \mathrm{pureza}$ radioquímica de $98,4 \%$.

Para capturar o ${ }^{14} \mathrm{CO}_{2}$, desprendido no processo de mineralização da ametrina, frascos de cintilação com $1 \mathrm{~mL}$ de solução de monoetanolamina foram colocados dentro dos recipientes com solo. Semanalmente, durante nove semanas, foram realizadas as trocas dos frascos coletores de $\mathrm{CO}_{2}$. A pós as trocas, foram adicionados aos frascos coletores $15 \mathrm{~mL}$ de solução cintiladora: $4 \mathrm{~g}$ de 2,5diphenyl-oxazole (PPO); 0,2 $\mathrm{g}$ de 1,4 bis [5-Phenyl 2-2-oxazolyl]- benzene, 2,2'- $p$-Phenylene-bis [phenyloxazole] (POPOP); $340 \mathrm{~mL}$ Renex 95\%; e $660 \mathrm{~mL}$ de tolueno (Mesquita \& Ruegg, 1984), e a radi oatividade de cada amostra foi avaliada, durante 15 min, em espectrômetro de cintilaçãolíquida (ELC) (Beckman-model o 5801).

Após nove semanas de incubação, foi realizada a extração dos resíduos e de seus metabólitos. Aos frascos com $10 \mathrm{~g}$ de amostra de solo de cada tratamento foram adicionados $10 \mathrm{~g}$ de sulfato de sódio anidro e $20 \mathrm{~mL}$ de metanol. Após duas horas de agitação (120 rpm) e 30 min de repouso, para decantação, o sobrenadante foi filtrado e o processo repetido por mais duas vezes, combinando os sobrenadantes. O volume final foi medido e $5 \mathrm{~mL}$ foram transferidos para frasco de cintilação. 0 solvente foi evaporado e então $15 \mathrm{~mL}$ de solução cintiladora foram adicionados e a radioatividade foi determinada. Alíquotas de $200 \mu \mathrm{L}$ do mesmo filtrado e $10 \mu \mathrm{L}$ da solução-padrão do herbicida radiomarcado foram aplicadas em placas de sílica gel $60 \mathrm{~F}_{254}$ (Merck). A el uição das placas foi efetuada com o sistema de solvente acetonitrila-água-ácido fórmico (94:5:1, v/v), de acordo com Burkard \& Guth (1976). O produto e os possíveis metabólitos foram visualizados com auxílio de luz ultravioleta (345$366 \mathrm{~nm}$ ), eas manchas foram confirmadas por autoradiografia.
Após a extração, ${ }^{14} \mathrm{C}$ remanescente como resíduo não-extraível das amostras de sol o foi determinado em oxidador biológico (Biological Material OxidizerBeckman), utilizando-se $1 \mathrm{~g}$ de amostra ecatal isador metálico $(\mathrm{CuO}) . \mathrm{O}^{14} \mathrm{CO}_{2}$ resultante da combustão foi coletado em $15 \mathrm{~mL}$ de solução cintiladora (3,3 g PPO; $600 \mathrm{~mL}$ tolueno; $300 \mathrm{~mL}$ éteretilenoglicol monometilico; $100 \mathrm{~mL}$ monoetanolamina), conforme Andrea et al. (1982), e quantificado em ELC.

O número de microrganismos (bactérias, fungos e actinomicetos) foi avaliado no início e no final do experimento pelo método de di luição e plaqueamento em meios de cultura seletivos. $\mathrm{Na}$ contagem das bactérias, fungos e actinomicetos, foram utilizados nutriente ágar, meio de Martin (Martin, 1950) e meio amido caseína (Kuster \& Williams, 1964), respectivamente.

\section{RESULTADOS E DISCUSSÃO}

O desprendimento de ${ }^{14} \mathrm{CO}_{2}$ da ametrina (F igura 1) indica que os tratamentos sem adição de solo rizosférico, (AQ e AQ/Est) apresentaram, após nove semanas de incubação, menor percentagem de ${ }^{14} \mathrm{CO}_{2}$ desprendido $(0,70$ e $0,58 \%$, respectivamente), ou seja, uma mineralização da ametrina. A maior quantidade de ${ }^{14} \mathrm{CO}_{2}$ desprendido foi do tratamento AQ/SRH (2,56\%), seguido por AQ/SR (1,25\%). Este aumento na taxa de degradação é conhecido como degradação acelerada (F el sot \& Dzantor, 1990) decorrente de aplicações sucessivas de um mesmo pesticida, ocorrendo adaptação da microbiota do solo na degradação de diversos produtos (Montei ro, 1997).

Comparando os parâmetros analisados dos tratamentos que o solo recebeu com a taxa de degradação, verifica-se que o tratamento $A Q / S R H$ apresentou 3,5 vezes mais ${ }^{14} \mathrm{CO}_{2}$ que os tratamentos $A Q$, evidenciando a adaptação dos microrganismos da rizosfera de cultura de cana-de-açúcar previamente tratada. Portanto, nestes campos, a degradação da ametrina deve ocorrer mais 


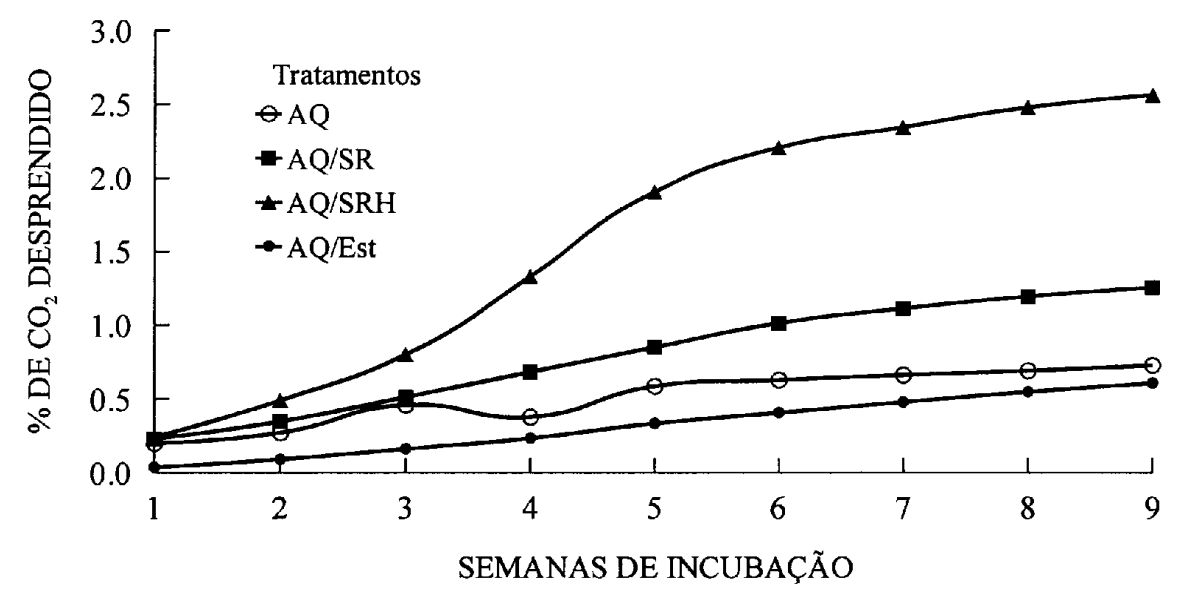

Figura 1. Percentagem relativa ao total aplicado de ${ }^{14} \mathrm{CO}_{2}$ desprendido em Areia Quartzosa (AQ), com adição de solo rizosférico não tratado (AQ/SR), com adição de solo rizosférico tratado (AQ/SRH) e Areia Quartzosa esterilizada (AQ/Est), durante nove semanas de incubação com ${ }^{14} \mathrm{C}$-ametrina.

rapidamente do que em campos sem aplicação. Costa et al. (1997) observaram que a adição ao sol o de 10\% de palhas de cana-de-açúcar tratadas previamente com ametrina e não tratadas aumentou em 13 e 12 vezes, respectivamente, a biodegradação da ametrina e concluíram que a degradação ocorreu por cometabolismo.

A quantidade do radiocarbono extraível (Figura 2) foi em média $55 \%$ do radiocarbono aplicado inicialmente para todos tratamentos $A Q$, AQ/SRH, AQ/SR e AQ/Est $(57,35 ; 62,93 ; 46,70$ e $52,41 \%$, respectivamente), enquanto o não-extraível ficou ao redor de $29 \%$ em média dos tratamentos
AQ, AQ/SRH, AQ/SR e AQ/Est (34,0; 29,06; 28,60 e $23,23 \%$, respectivamente). De acordo com $\mathrm{Führ} \&$ Mittelstaedt (1980), o processo de formação de resíduos não-extraíveis de pesticidas nos sol os está relacionado principalmente com a matéria orgânica dos sol os, uma vez quea fração orgânica do sol o tem potencial para formar ligações químicas estáveis com pesticidas e, ou, seus produtos de degradação. A fração deresíduos extraíveis éa fração que está mais biodisponível no solo, enquanto a fração nãoextraível se encontra mais estável, entretanto, a liberação desses resíduos depende, principalmente, da ação dos microrganismos (Scheunert et al., 1986).

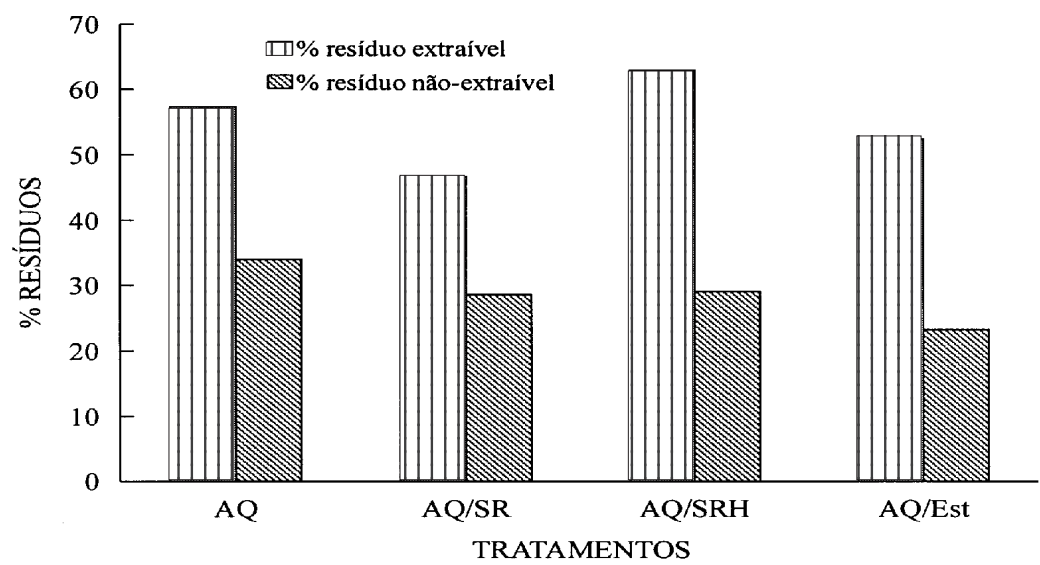

Figura 2. Percentagem relativa ao total aplicado de resíduo extraível e resíduo não-extraível em Areia Quartzosa (AQ), com adição de solo rizosférico não tratado (AQ/SR), com solo rizosférico tratado (AQ/SRH),) e Areia Quartzosa esterilizada (AQ/Est), durante nove semanas de incubação com ${ }^{14} \mathrm{C}$ ametrina. 
Os tratamentos que não receberam adição de substratos ( $A Q$ e AQ/Est) apresentaram os metaból itos de Rfs 0,11 e0,63 junto com a ametrina, Rf igual a 0,73, e o tratamento com a adição de solo rizosférico resultou no aparecimento de um metabólito a mais de Rf 0,21. Pode-se verificar, então, a formação de produtos que provavelmenteseadsorveram (Figura 2) de formas diferentes do produto mãe (Hsu \& Bartha, 1976; Katan \& Lichtenstein, 1977; Lichtenstein, 1980).

O quadro 2 mostra que a presença da ametrina nos tratamentos com adição de solo rizosférico aumentou o número de microrganismos, principalmente bactérias. É provável que este aumento da população de microrganismos tenha sido o principal responsável pela mineralização da ametrina. Evidências de que a ametrina seria degradada por bactérias do sol o foram também observadas por Cook \& Hütter (1982).

Assim, pelo aumento do desprendimento de ${ }^{14} \mathrm{CO}_{2}$, aparecimento de metabólitos e número de microrganismos, a adição em areia quartzosa desol os derizosfera, com esem aplicação prévia de ametrina, houve aumento na mineralização de ${ }^{14} \mathrm{C}$-ametrina, indicando que a presença de plantas facilita a degradação de xenobióticos. Tal degradação pode ocorrer particularmente quando o contaminante orgânico é degradado cometabolicamente, uma vez que a rizosfera provê um ambiente condutivo de transformações cometabólicas (Cunningham et al., 1996). Neste processo, o composto não é utilizado para gerar energia ou crescimento microbiano da população degradadora, mas a atividade microbiana é muito importante.

\section{CONCLUSÃO}

A mineralização da ametrina é de origem microbiológica e o enriquecimento do solo arenoso com solo rizosférico aumenta a degradação desse herbicida. O aumento pode ser ainda maior quando se realizam aplicações prévias desse herbicida.

\section{LITE RATURA CITADA}

ABDEL-NASSER, M.; MAKAWI, A.A. \& ABDEL-MONEIM, A.A. Occurrence of certain microorganisms in rhizosphere soils of common bean and cotton as affected by the application of Temik or orthocide pesticides. Egyptian J. Microbiol. 14:37-44, 1979.

ANDERSON, T.A.; GUTHRIE, E.A. \& WALTON, B.T. Bioremediation in the rhizosphere. Environ. Sci. Techn., 27:2630-2636, 1993.

ANDREA, M.M.; LORD, K.A.; BROMILOW, R.H. \& RUEGG, E. Degradation of parathion by soil kept moist with and without repeated applications. Environ. Pollut., 27:167-177, 1982.

BALASUBRAMANIAN, A. \& RANGASWANI, G. Influence of foliar application of chemicals on the root exudations and rhizosphere microflora of Sorghum vulgareand Crotalaria juncea. Fol ha Microbiol., 18:492-498, 1973.

BURKHARD, N. \& GUTH, J .A. Photodegradation of atrazine, atraton and ametryne in aqueous solution with acetone as a photosensitiser. Pest. Sci., 7:65-71. 1976.

CAMPBELL, R. Plant microbiology, Baltimore, Edward Arnold, 1985. 191p.

COMPTE, V.X. Avaliação de metodol ogias de col eta de ${ }^{14} \mathrm{CO}_{2} \mathrm{em}$ estudos de biodegradação de agroquímicos em solos. Piracicaba, Universidade de São Paulo, 1997. 55p. (Tese de Mestrado)

COOK, A.M. \& HÜTTER, R. Ametryneand prometryneas sulfur source for bacteria. Appl. Environ. Microbiol., 43:781-786, 1982.

COSTA, M.A. Biodegradação de 14C-Ametrina em areia quartzosa com adição de palha de cana e solo rizosférico. Piracicaba, Universidade deSão Paulo, 1992. 107p. (Tese de Mestrado)

Quadro 2. Unidades formadoras de colônias (UFC) por grama de solo, no início e após nove semanas de incubação de Areia Quartzosa (AQ), com adição de solo rizosférico não tratado (AQ/RS) e tratado com herbicida ametrina (AQ/SR H) e solo esterilizado (AQ/E st)

\begin{tabular}{|c|c|c|c|c|c|c|c|c|}
\hline \multirow{2}{*}{ Tratamento } & \multicolumn{2}{|c|}{ Bactéria $1 * 10^{5}$} & \multicolumn{2}{|c|}{ F ungos $1 * 10^{4}$} & \multicolumn{2}{|c|}{ Actino $1 * 10^{3}$} & \multicolumn{2}{|c|}{ Média $1 * 10^{5}$} \\
\hline & Zero & 64 dias & Zero & 64 dias & Zero & 64 dias & Zero & 64 dias \\
\hline $\mathrm{AQ}$ & 4 & 5 & 5 & 3 & 3 & 300 & 4,53 & 8,83 \\
\hline AQ/SR & 5 & 20000 & 10 & 20 & 5 & Zero & 6,25 & 18000 \\
\hline $\mathrm{AQ} / \mathrm{SRH}$ & 0,01 & 30 & 2 & 0,7 & 6 & Zero & 0,27 & 29 \\
\hline AQ/Est. & Zero & 40 & Zero & Zero & Zero & Zero & Zero & 13 \\
\hline
\end{tabular}


COSTA, M.A.; MONTEIRO, R.T.R. \& TORNISIELO, V.L. Influência da adição da palha de cana-de-açúcar na degradação de ${ }^{14 C}$-ametrina em solo areia quartzosa. Sci. Agric., 54:117-122, 1997.

CUNNINGHAM, S.D.; ANDERSON, T.A.; SCHWAB, A.P. \& HSU, F.C. Phytoremediation of soils contaminated with organic pollutants. Adv. Agron., 56:55-114, 1996.

FELSOT, A.S. \& DZANTOR, E.K. Enhancing biodegradation for detoxification of herbicide waste in soil. In: RACKE, J.K. \& COATS, J .R. Enhanced biodegradation of pesticides in the environment, Washington, D.C., ACS, 1990. p.249-268 (ACS. Symposium Series, 426)

FÜHR, F. \& MITTELSTAEDT, W. Plant experiments on the biovailability of unextracted (carbonyl-14C) methabeenzthiazuron residues from soil. J . Agric. Food Chem., 28:122-125, 1980.

GEBENDINGER, N. \& RADOSEVICH, M. Inhibition of atrazine degradation by cyanazine and exogenous nitrogen in bacterial isolate M91-3. Appl. Microbiol. Biot., 51:375-381, 1999.

HSU, T.S. \& BARTHA, R. Hydrolizable and nonhydrolizabel 3,4dichloroaniline - humus - complexes and their respective rates of biodegradation. J . Agric. Food Chem., 24:118-122, 1976.

INSTITUTO BRASILEIRO DA AMAZONIA E DO MEIO AMBIENTE - IBAMA. Manual de testes para avaliação da ecotoxidade deagentes químicos. 2.ed. Brasília, 1990. 351p.

KATAN, J . \& LICHTENSTEIN, E.P. Mechanisms of production of soil-bound residues of ${ }^{14} \mathrm{C}$-parathion by microrganisms. J . Agric. Food Chem., 25:1404-1408, 1977.

KONTCHOU, C.Y. \& GSCHWIND, N. Biodegradation of s-triazine compounds by a stable mixed bacterial community. Ecotoxicol. Environ. Saf., 43:47-56, 1999

KUSTER, E. \& WI LLIAMS, S.T. Selection of media for isolation of Streptomycetes. Nature, 202:928-929, 1964.

LEON, L.; MANUEL, C. \& BORNEMISZA, E. Residuos, degradación y comportamiento de la ametrina en un vertisol de Guanacaste, Costa Rica. Turialba, 28:3-7, 1978.
LICHTENSTEIN, E.P. Bound residues in soils and tranfer of soil residues in crops. Resid. Rev., 76:147-153, 1980.

LUI, L.C. \& CIBES-VIADÉ, H. Effect of various herbicides on the respiration of soil microorganisms. J . Univ. Puerto Rico, 56:17, 1972.

MARTIN, J .P. Use of acids rose-bengall and streptomicin in the plate method for estimating soil fungi. Soil Sci., 134:15381539,1950

MESQUITA, T.B. \& RUEGG, E.F. Influência de agentes tensoativos na detecção da radição Beta. Cienc. Cult., 36:446-450, 1984.

MONTEIRO, R.T.R. Biodegradação de pesticidas. In: MELO, I.S. \& AZEVEDO, J.L., eds. Microbiologia ambiental. J aguariúna, EMBRAPA, CNPMA, 1997. p.107-124.

PRATA, F.P. Biodegradação e adsorção dos herbicidas diuron e ametrina em sol os tratados com vinhaça. Piracicaba, Escola Superior de Agricultura Luiz de Queiroz, 1998. 73p. (Tese de Mestrado)

RODRIGUES, B.N. \& ALMEIDA, F.S. Guia de herbicidas, Londrina, IAPAR, 1995. 675p.

SANDMANN, E. \& LOOS, M.A. Enumeration of 2,4-D degrading microorganisms in soils and crop plant rhizospheres using indicator media: high populations associated with sugarcane (Saccharum officinarum). Chemosphere, 13:1073-1084, 1984

SCHEUNERT, I.; MEER-BEKK, C.T. \& KORT, F. Distribuition and biodegradability of ${ }^{14} \mathrm{C}$-residues bond in varios soil fractions after treatment of the soil with model ${ }^{13} \mathrm{C}$ chemicals. In: International Atomic Energy Agency. Quantification, nature and bioavailability of bound ${ }^{14} \mathrm{C}$ pesticide residues in soil, plant and food. Vienna, 1986. p.31-40.

ZABLOTOWIEZ, R.M.; HOAGLAND, R.E.; LOCKE, M.A. \& HICKEY, W.J. Glutathione-S-transferase activity and metabolism of glutathione conjugates by rhizosphere bacteria. Appl. Environ. Microbiol., 61:1045-1060, 1995. 